\title{
Dual MET-EGFR combinatorial inhibition against T790M-EGFR-mediated erlotinib-resistant lung cancer
}

\section{Z Tang ${ }^{1,6}$, R Du ${ }^{1,6}$, S Jiang', C Wu $\mathbf{u}^{2,3,4}$, DS Barkauskas ${ }^{2,3,4}$, J Richey ${ }^{2,3,4}$, J Molter $^{2,3,4}$, M Lam $^{4}$, C Flask $^{2,3,4}$,

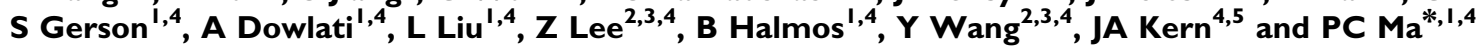

'Division of Hematology/Oncology, Department of Medicine, Case Western Reserve University, University Hospitals Case Medical Center, Cleveland, OH, USA; ${ }^{2}$ Department of Radiology, Case Westem Reserve University, University Hospitals Case Medical Center, Cleveland, OH, USA; ${ }^{3}$ Case Center for Imaging Research, University Hospitals Case Medical Center, Cleveland, OH, USA; ${ }^{4}$ Case Comprehensive Cancer Center, Cleveland, OH, USA; ${ }^{5}$ Division of Pulmonary, Critical Care and Sleep Medicine, Department of Medicine, Case Western Reserve University, University Hospitals Case Medical Center, Cleveland, $\mathrm{OH}$, USA

Despite clinical approval of erlotinib, most advanced lung cancer patients are primary non-responders. Initial responders invariably develop secondary resistance, which can be accounted for by T790M-EGFR mutation in half of the relapses. We show that MET is highly expressed in lung cancer, often concomitantly with epidermal growth factor receptor (EGFR), including HI975 cell line. The erlotinib-resistant lung cancer cell line HI975, which expresses L858R/T790M-EGFR in-cis, was used to test for the effect of MET inhibition using the small molecule inhibitor SUII274. HI975 cells express wild-type MET, without genomic amplification (CNV = I.I). At $2 \mu \mathrm{M}$, SUI 1274 had significant in vitro pro-apoptotic effect in HI 975 cells, 3.9-fold $(P=0.00$ I 5) higher than erlotinib, but had no effect on the MET and EGFR-negative H520 cells. In vivo, SUI I 274 also induced significant tumour cytoreduction in HI975 murine xenografts in our bioluminescence molecular imaging assay. Using small-animal microPET/MRI, SUII 274 treatment was found to induce an early tumour metabolic response in HI975 tumour xenografts. MET and EGFR pathways were found to exhibit collaborative signalling with receptor cross-activation, which had different patterns between wild type (A549) and L858R T790M-EGFR (HI975). SUI 1274 plus erlotinib/CL-387,785 potentiated MET inhibition of downstream cell proliferative survival signalling. Knockdown studies in HI975 cells using siRNA against MET alone, EGFR alone, or both, confirmed the enhanced downstream inhibition with dual MET-EGFR signal path inhibition. Finally, in our time-lapse video-microscopy and in vivo multimodal molecular imaging studies, dual SUI I274-erlotinib concurrent treatment effectively inhibited HI975 cells with enhanced abrogation of cytoskeletal functions and complete regression of the xenograft growth. Together, our results suggest that MET-based targeted inhibition using small-molecule MET inhibitor can be a potential treatment strategy for T790M-EGFR-mediated erlotinib-resistant non-small-cell lung cancer. Furthermore, optimised inhibition may be further achieved with MET inhibition in combination with erlotinib or an irreversible EGFR-TKl.

British Journal of Cancer (2008) 99, 91।-922. doi: I0.1038/sj.bjc.6604559 www.bjcancer.com

Published online 26 August 2008

(c) 2008 Cancer Research UK

Keywords: MET; EGFR; inhibitor; erlotinib; resistance; lung cancer

Receptor tyrosine kinases (RTKs) play a key role in lung cancer tumorigenesis and progression (Choong et al, 2005). Progress has been made in the treatment of advanced non-small-cell lung cancer (NSCLC) using small-molecule tyrosine kinase inhibitors (TKIs) gefitinib and erlotinib, targeting epidermal growth factor receptor (EGFR) (Lynch et al, 2006). EGFR kinase domain mutations (frequently L858R) and exon 19 deletions have been identified to be predictive of response to gefitinib/erlotinib (Shigematsu and Gazdar, 2006; Sharma et al, 2007). Although erlotinib was shown to prolong survival in a large phase III

*Correspondence: Dr PC Ma, Division of Hematology/Oncology, Department of Medicine, Case Western Reserve University, University Hospitals Case Medical Center, Ireland Cancer Center, and Case Comprehensive Cancer Center, 10900 Euclid Avenue, WRB 2-123, Cleveland, OH 44I06, USA; E-mail: patrick.ma@case.edu

${ }^{6}$ These authors contributed equally to the work.

Received 26 March 2008; revised 15 July 2008; accepted 17 July 2008; published online 26 August 2008 randomised trial (NCIC-BR.21) (Shepherd et al, 2005), the majority of unselected lung cancer patients are still primary nonresponders. Patients whose cancer has wild-type EGFR genotype are generally non-responders but may at best derive stable disease from the TKIs. Initial responders with mutant EGFR invariably develop secondary resistance and soon succumb to the disease. At least half of the acquired resistance is mediated by the 'gatekeeper' mutation T790M-EGFR (Kobayashi et al, 2005a; Pao et al, 2005). Moreover, T790M was found in the H1975 cell line, in combination with L858R, which was previously established without prior exposure to EGFR TKIs. Hence, T790M may also have a role in primary EGFR-TKI resistance. Currently, there are still no Federal Drug Administration (FDA)-approved clinical inhibitors that can overcome T790M-mediated EGFR-TKI resistance yet.

The MET receptor has been shown to be an important molecule in a variety of malignancies (Tsarfaty et al, 1994; Schmidt et al, 1997, 1998, 1999; Birchmeier et al, 2003; Ma et al, 2003b; Benvenuti and Comoglio, 2007), and has recently been validated as an 
912

attractive therapeutic target in cancer therapy, including lung cancer (Ma et al, 2003a, 2005a, b; Christensen et al, 2005; Salgia, 2006). Overexpression of MET or its ligand HGF have been found to confer a poor prognosis (Ma et al, 2003b; Miyata et al, 2006; Garcia et al, 2007; Sawada et al, 2007). Dysregulation of the MET-HGF signalling axis upregulates diverse tumour cell functions, including cell proliferation, survival, cell scattering and motility, epithelial-mesenchymal transition, angiogenesis, invasion, and metastasis (Corso et al, 2005; Dietrich et al, 2005; Ma et al, 2005a; Peruzzi and Bottaro, 2006). Reversible small-molecule inhibitors such as SU11274 targeting MET have been developed for therapeutic inhibition (Christensen et al, 2003; Sattler et al, 2003; Ma et al, 2005a, b). We hypothesised that MET signalling plays a key role in lung cancer oncogenic signalling and optimised therapy targeting MET would be effective as a treatment strategy in the face of EGFR-TKI resistance. In this study, we sought to define the role of MET signalling in EGFR-TKI-resistant lung cancer. Furthermore, using a combination of small-molecule kinase inhibitors and short-interfering RNA (siRNA), we examined the role of MET inhibition, either alone or combined with EGFR inhibition, using both in vitro and in vivo assays against the EGFRTKI-resistant lung cancer cell line H1975 (L858R/T790M-mutant EGFR). Our data support the potential role of dual TKI combinatorial inhibition using EGFR inhibitors to enhance MET inhibition in T790M-EGFR-mediated therapy resistance.

\section{MATERIALS AND METHODS}

Cell culture, cell lysates preparation, immunoprecipitation, and immunoblotting

Lung cancer cell lines were obtained from American Type Culture Collection and grown in RPMI 1640 (Hyclone, Logan, UT, USA), $10 \%(\mathrm{v} / \mathrm{v})$ foetal bovine serum (FBS) as instructed under standard cell culture conditions. For growth factor stimulation studies, human HGF (50 $\mathrm{ng} \mathrm{ml}^{-1}$ ) (R\&D Systems, Minneapolis, MN, USA) and human EGF (100 $\mathrm{ng} \mathrm{m}^{-1}$ ) (Calbiochem, Cambridge, MA, USA) were used as indicated. Cellular proteins were extracted from whole cells as previously described (Choong et al, 2006). Immunoprecipitation (IP) studies and immunoblotting (WB) were performed as previously described (Maulik et al, 2002; Choong et al, 2006) using the following primary antibodies as indicated: p-MET[Y1234/1235] (i.e., pY1252/1253 as in the full-length MET version) (Cell Signaling, Danvers, MA, USA), MET (C-12, Santa Cruz Biotechnology, Santa Cruz, CA, USA), p-EGFR[Y1068] (Cell Signaling), EGFR (Santa Cruz Biotechnology), p-ERBB3[Y1289] (Cell Signaling), p-AKT[S473] (Cell Signaling), AKT (BiosourceInvitrogen, Carlsbad, CA, USA), p-extracellular signal-regulated kinases 1 and 2 (ERK1/2)[T202/Y204] (Cell Signaling), ERK1/2 (Biosource-Invitrogen), p-STAT3[Y705] (Cell Signaling), STAT3 (Zymed-Invitrogen, Carlsbad, CA, USA), phosphotyrosine (p-Tyr; Upstate-Millipore, Billerica, MA, USA), and Actin (Santa Cruz Biotechnology).

\section{Chemicals}

SU11274: [(3Z)-N-(3-chlorophenyl)-3-(\{3,5-dimethyl-4-[(4-methylpiperazin-1-yl)carbonyl]-1H-pyrrol-2-yl $\}$ methylene)- $N$-methyl-2-oxo2,3-dihydro- $1 H$-indole-5-sulphonamide] (Ma et al, 2005a) and CL-387,785 were purchased from EMD-Calbiochem (Cambridge, MA, USA), dissolved in DMSO, and used at the indicated concentrations. Erlotinib was prepared as previously described (Choong et al, 2006).

Genomic studies of MET gene DNA extraction and DNA sequencing: Genomic DNA of H1975 cells were extracted using Qiagen DNAeasy Kit (Qiagen, Valencia, CA, USA) according to the manufacturer's instructions. Direct DNA sequencing of the complete $M E T$ gene was performed as previously described (Ma et al, 2005a).

Quantitative real-time polymerase chain reaction (QPCR): Genomic copy number variation of the $M E T$ gene was determined in triplicate using QPCR with the RNaseP as the reference gene. Quantitative realtime polymerase chain reactions were performed in ABI PRISM 7900HT System and the reaction conditions are available upon request. The QPCR primers for MET copy number variation determination were purchased from ABI (ABI assay no.: Hs01565582_g1).

Cellular apoptosis and viability assay: For cellular apoptosis assays, cells were plated separately in triplicate in six-well plates in 10\% FBS-containing media. Drug inhibitor treatment using erlotinib, SU11274, or DMSO control as indicated was added the next day, with the cells incubated for $72 \mathrm{~h}$ further. Cellular apoptosis was determined by fluorescence-activated cell sorting (FACS) analysis using the Annexin-V-Fluos Staining Kit (Roche Diagnostics, Mannheim, Germany) according to the manufacturer's instructions. Cellular apoptosis assays were performed in triplicate. Cellular viability assays were performed using the Trypan-Blue Dye Exclusion assay with duplicate counting using standard haemacytometer-light microscopy, with each experiment further repeated in duplicate.

\section{Time-lapsed video microscopy and image analysis of cytoskeletal functions}

H1975 cells were plated on cell culture dishes and placed into a temperature-controlled chamber at $37^{\circ} \mathrm{C}$ in an atmosphere of $5 \%$ $\mathrm{CO}_{2}$. The cells were examined by and recorded under video microscopy using an Leica $6000 \mathrm{~B}$ inverted microscope, Pecon incubation chamber, and Retiga EXI 12 bit camera (Q imaging, Vancouver, BC, Canada) with MetaMorph image analysis software (Universal Imaging, Downington, PA, USA) (details see also Supplementary Materials and Methods).

Lentivirus transduction of luciferase-expressing vector (a) Lentivirus production: Plasmids. The packaging plasmid pCMVÄR8.91, the vesicular stomatitis virus glycoprotein G (VSV.G), and encoding plasmid pCSO-rre-cppt-MCU3-LUC were kind gifts from Dr Donald B Kohn (University of Southern California). Virus production. Transfection with transfer vector, packaging plasmid and envelope plasmid were performed by calcium phosphate precipitate $12 \mathrm{~h}$ after planting package $293 \mathrm{~T}$ cells into $10 \mathrm{~cm}$ cell culture dishes. (b) Lentiviral transduction of EGFR-TKI-resistant lung tumour cells: Medium from the package cell culture was then collected and centrifuged at 3000 r.p.m. for $5 \mathrm{~min}$ at room temperature, followed by filtering through $0.45 \mu \mathrm{m}$ filter. The filtered medium containing virus particles was then added to the target transduction cells (H1975), which were plated the day before transduction.

\section{In vivo murine xenograft model}

Six-week-old female Ncr-nu (Nude) mice were purchased from Charles River Laboratories (Wilmington, MA, USA) and hosted in the pathogen-free animal facility at the Case Western Reserve University. In vivo animal studies were performed according to institution-approved protocols and guidelines. Xenografts of the luciferase-expressing H1975 lung cancer cells were established by intradermally injecting $3 \times 10^{6}$ viable cells in RPMI 1640 media into the flank/leg region of nude mice to produce subcutaneous tumours. Indicated treatments with targeted TKIs were given at the time when tumour xenografts were beginning to be visible (corresponding to 7 days post-implantation of $\mathrm{H} 1975$ cells). In vivo daily inhibitor drug treatments were performed as indicated. SU11274 was administered as intratumoral injections, whereas erlotinib was administered using oral gavage. Body weight was recorded for each animal twice weekly to monitor potential 
toxicities. Tumour xenografts were subsequently dissected and harvested at the end of the experiments, formalin-fixed, and stained with haematoxylin and eosin (H\&E) using standard techniques.

Small animal in vivo imaging (a) Bioluminescence imaging (BLI): Xenograft tumour growth of H1975-luc cells were monitored by non-invasive luciferase-bioluminescence molecular imaging. Mice were imaged by BLI using a Xenogen IVIS ${ }^{\mathbb{R}} 200$ bioluminescence scanner (Xenogen, Hopkinton, MA, USA) at indicated times on the pretreatment day as baseline, and then on various post-TKI treatment days as specified (details see also Supplementary Materials and Methods). (b) MicroPET/magnetic resonance imaging (MRI) imaging: For microPET/MRI imaging study, H1975 tumour xenografts were allowed to grow to a readily visible size in a total of 7 days post-implantation to ensure adequate baseline micro-PET uptake. H1975 tumour xenografts were treated with (a) diluent control and (b) SU11274 (100 $\mu \mathrm{g}$ per xenograft). The nude mice were subjected to MRI (Bruker Biospec 7T MRI scanner, Bruker BioSpin MRI, Billerica, MA, USA) and microPET scanning (R4 micro-PET system, Siemens Medical Solutions, Knoxville, TN, USA) at the indicated time of treatment (details see also Supplementary Materials and Methods).

\section{siRNA inhibition}

Specific siRNAs targeting human MET or EGFR mRNA, ONTARGET plus SMARTpool, were purchased from Dharmacon Inc. (Chicago, IL, USA). The siRNA duplexes were transiently transfected using DharmaFECT 1 Transfection reagent (Dharmacon Inc.) according to the manufacturer's instructions. Control transfection using scrambled siRNA was performed in parallel using ON-TARGETplus siCONTROL siRNA (Dharmacon Inc.).

\section{Statistical analysis}

Statistical significance was tested by two-tailed Student's $t$-test, with $P$-value of less than 0.05 considered statistically significant.

\section{RESULTS}

\section{Co-expression of MET and EGFR in lung cancer}

We first examined the expression pattern of MET and EGFR in lung cancer cell lines. Nine of 11 NSCLC cell lines (82\%) (except H520 and H661) (see Supplementary Table 1 for baseline characteristics of the cell lines) co-expressed both MET and EGFR, including the H1975 cell line (Figure 1). Signal transducer and activator of transcription 3 (STAT3) is a common downstream signalling target for both MET and EGFR, and has been shown to be crucial in mediating the oncogenic potential of mutant EGFR signalling (Song et al, 2003). STAT3 was ubiquitously expressed in all the cell lines examined.

\section{SU11274 induces apoptosis and inhibition of cytoskeletal functions in erlotinib-resistant H1975 lung cancer cells expressing L858R/T790M-EGFR}

As we found that many NSCLC cell lines co-express EGFR and MET, including H1975 cells, we first investigated if MET inhibition using the small-molecule inhibitor SU11274 can be effective in the erlotinib-resistant H1975 cells. H1975 cell line was chosen because it expresses the 'gatekeeper'-resistant T790M-EGFR mutation (in-cis with L858R) in the receptor kinase domain hydrophobic pocket, representing a major mechanism of resistance to reversible EGFR-TKI (erlotinib/gefitinib) (Kobayashi et al, 2005a; Pao et al, 2005). SU11274 was previously characterised as a reversible inhibitor of MET, inhibiting specific tyrosine phosphorylation of the juxtamembrane CBL-binding phosphosite (pY1003), the major kinase autophosphorylation sites (pY1234/1235), as well as downstream signalling (Sattler et al, 2003; Ma et al, 2005a). It exhibits

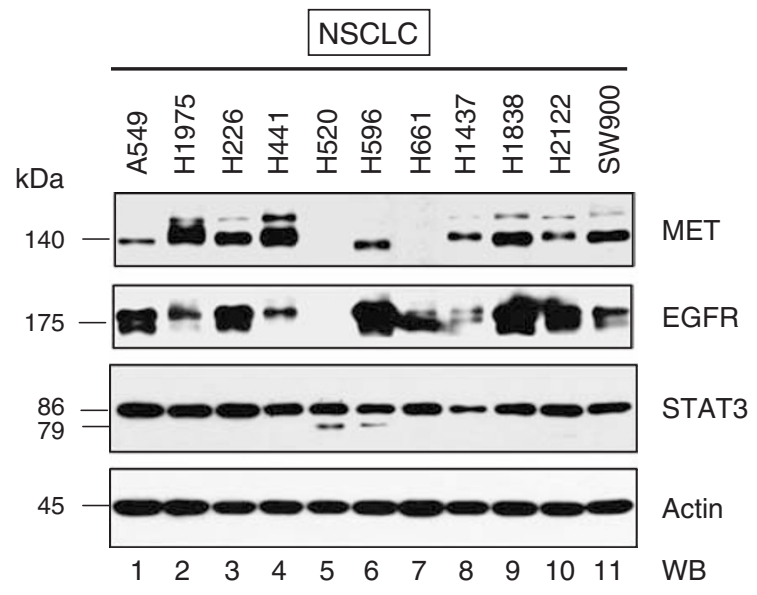

Figure I Co-expression pattern of MET and EGFR in lung cancer. The expression pattern of MET (Ist panel) and EGFR (2nd panel) was examined using standard immunoblotting of the whole cell lysates (WCLs) from the following lung cancer cell lines cultured under serum-containing conditions (I0\% FBS): A549, HI975, H226, H44I, H520, H596, H66I, HI437, HI838, H2122, and SW900. The downstream signalling effector STAT3 (3rd panel) was also included in the immunoblot analysis. $\beta$-Actin was included as loading control (bottom panel).

$>60$-fold selectivity for MET over FLK and $>400$-fold selectivity over RON, FGFR-1, SRC, CDK2, PDGFR- $\beta$, EGFR, and Tie-2 (Ma et al, 2005a). Here, we tested the pro-apoptotic effect of SU11274 treatment, in comparison to erlotinib, in the EGFR-TKI-resistant cell line H1975 (L858R/T790M-EGFR, wild-type KRAS). SU11274 at $2 \mu \mathrm{M}$ induced apoptosis (Annexin V- and propidium iodide-stained positive cells) in $14.8 \pm 2.4 \%$ of T790M-EGFR expressing H1975 cells, which is 5.5 -fold $(P<0.001)$ higher than diluent control and 3.9-fold $(P=0.0015)$ higher than erlotinib. To further demonstrate that the pro-apoptotic effect of SU11274 seen above was not a result of off-target effects, we also tested the EGFR-negative and MET-negative H520 cell line as negative control. SU11274 at $5 \mu \mathrm{M}$ did not result in any significant apoptosis in H520 cells $(0.44 \pm 0.30 \%, P=0.22)$. Similarly, $\mathrm{H} 520$ cells were also insensitive to erlotinib without any significant apoptosis induced by the drug $(0.3 \pm 0.1 \%, P=0.35)$ (Figure 2).

\section{SU11274 induces cytoreduction of erlotinib-resistant H1975 tumour xenograft in vivo}

To further test the role of MET inhibition in EGFR-TKI-resistant lung cancer in vivo, we developed stable luciferase-expressing H1975 lung cancer cells using lentivirus transduction. These cells were used in an in vivo xenograft model coupled with multimodal molecular imaging for non-invasive monitoring of xenograft growth and tumour response to TKI. Daily treatment with the MET inhibitor SU11274 caused statistically significant interval retardation of the xenograft tumour growth of H1975 cells with a ninefold reduction $(P=0.0251)$ in the xenograft growth, when compared with the diluent control, during the treatment period (Figure 3A-a,b). At the end of treatment period, SU11274-treated H1975 xenograft tumour BLI flux remained essentially unchanged at $104 \%(P=0.0251)$, when compared to $905 \%$ as seen in the diluent control (Figure 3A-a,b). Histological analysis of the tumour xenografts harvested at the end of the experiment confirmed the presence of intense tumour necrosis in the SU11274-treated animals, but not in the diluent control (Figure 3A-c). Both EGFR and MET signal pathways are functional and ligand-sensitive in the erlotinib-resistant H1975 cells. HGF stimulated downstream signal path activation in AKT (survival) and the mitogen-activated protein kinase ERK1/2 (proliferation-differentiation), as surrogate markers for MET inhibition were both abrogated in the H1975 cells by 


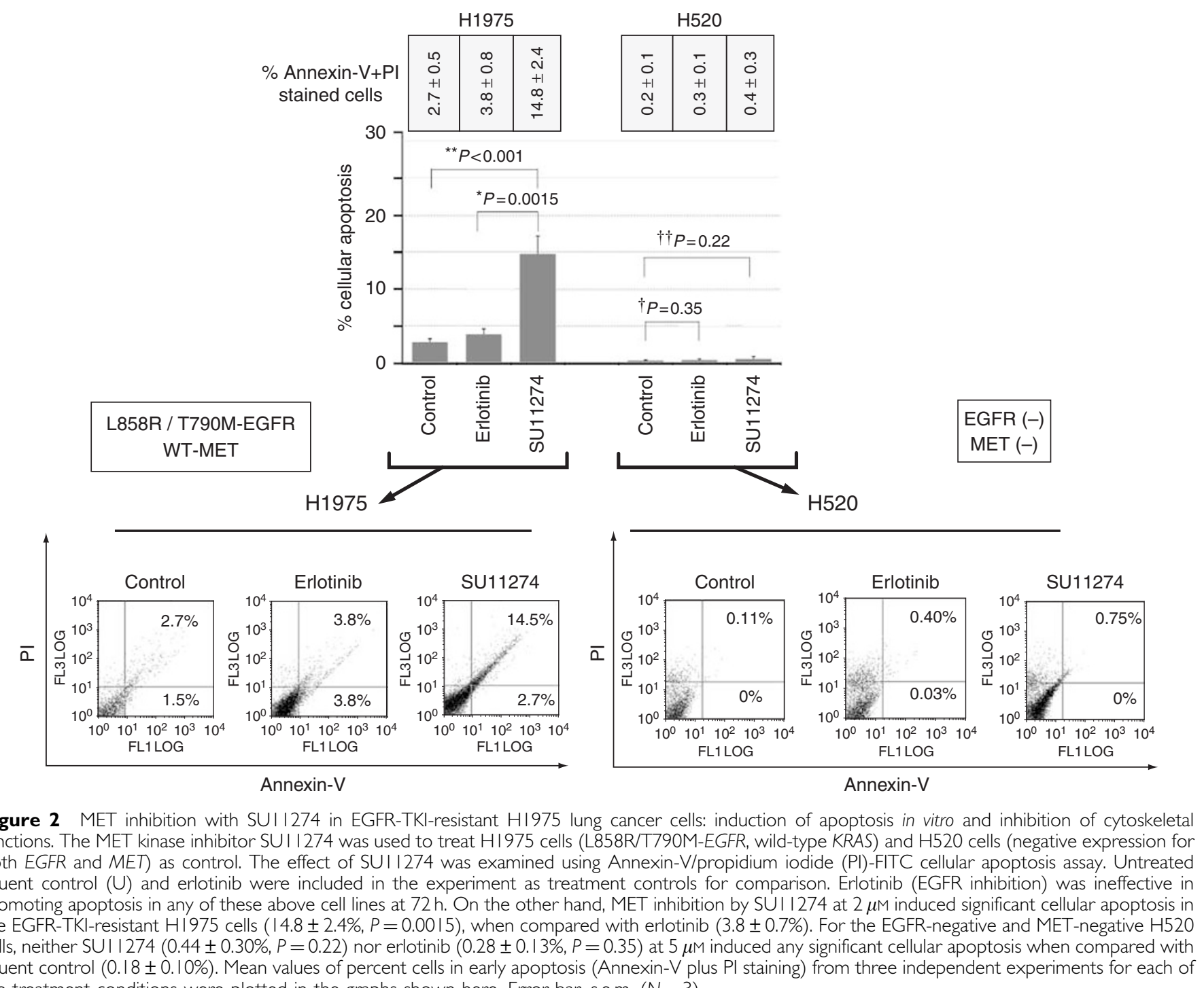
diluent control $(0.18 \pm 0.10 \%)$. Mean values of percent cells in early apoptosis (Annexin- $V$ plus Pl staining) from three independent experiments for each of the treatment conditions were plotted in the graphs shown here. Error bar, s.e.m. $(N=3)$.

SU11274 treatment in vitro (Figure 3A-d). Furthermore, we also showed that SU11274 inhibition effectively induced erlotinib-resistant A549 xenograft cytoreduction in vivo (Supplementary Figure 1).

\section{SU11274 inhibition induces early tumour response of the H1975 in vivo xenograft evident in microPET/MRI studies}

We focused further on the H1975 cell line to investigate whether MET inhibition with SU11274 induced H1975 xenograft tumour response in terms of glucose metabolism as monitored by in vivo FDG-PET (glucose analogue $\left[{ }^{18} \mathrm{~F}\right]$ fluoro-2-deoxy-D-glucose-positron emission tomography) studies with MRI co-registration. In vivo SU11274 inhibition induced a metabolic tumour response in $\mathrm{H} 1975$ xenografts within $24 \mathrm{~h}$ of the first treatment dose (Figure $3 \mathrm{~B}$ and C). Although the changes of the calculated xenograft tumour volumes between the two treatment groups did not differ significantly $(P>0.05)$ (Figure $3 \mathrm{~B})$, the SU11274-treated xenografts had statistically significant lower glucose metabolism by $45 \%(P=0.0226)$, when compared to diluent control (Figure 3B and C) (also see Supplementary Figure 2).

\section{MET-EGFR signalling cross-activation in lung cancer}

As MET and EGFR often co-express in lung cancer cells (Figure 1), we asked if there is signalling cross-activation between MET and EGFR pathways. Both A549 (wild-type EGFR) and H1975 (L858R/T790M-EGFR) cell lines were used as models for the signalling studies (Figure 4). Here, MET and EGFR signal transduction pathways were both shown to be functional and ligand-sensitive, although H1975 cells have higher serumindependent constitutively activated MET and EGFR. Enhanced and more durable downstream signalling activation was observed in phospho-AKT (survival), phospho-ERK1/2 (proliferation-differentiation), and phospho-STAT3 (transcriptional activation) when A549 and H1975 cells were co-stimulated with dual-ligand (HGF and EGF) (Figure 4A; see lanes 4, 7, 11, and 14). Immunoprecipitation studies of the MET and EGFR under single- or dual-ligand stimulation confirmed the presence of receptor cross-activation between MET and EGFR in these lung cancer cell lines (Figure 4B). In A549 cells, HGF was capable of activating EGFR in the presence of EGF, whereas in H1975, EGF activated MET with and without co-stimulation with HGF.

\section{MET is activated with no genomic amplification or mutations in H1975 lung adenocarcinoma cells}

Using standard QPCR technique, we determined the MET genomic copy number in several NSCLC cell lines, namely A549, 
H1975, H441, H520, H596, and H661. None of the cell lines examined exhibited $M E T$ genomic amplification. MET genomic copy number in H1975 was found to be 1.1, whereas that of A549 being 1.0 for comparison (Figure 4B). Direct DNA sequencing of the MET gene in H1975 did not reveal any non-synonymous mutations.
Dual inhibition with SU11274 plus erlotinib/CL-387,785 potentiates the MET-targeted inhibitory efficacy in erlotinib-resistant lung cancer cells

As both MET and EGFR are functional in erlotinib-resistant cell lines such as A549 and H1975 cells, and there is signalling
A

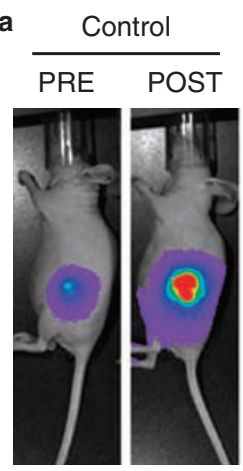

H1975 xenograft

c

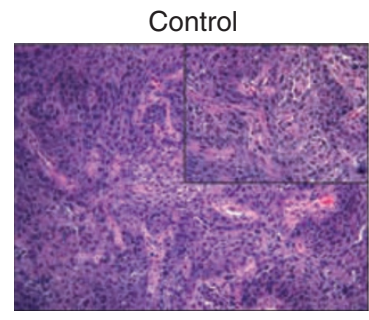

H1975 xenograft

B
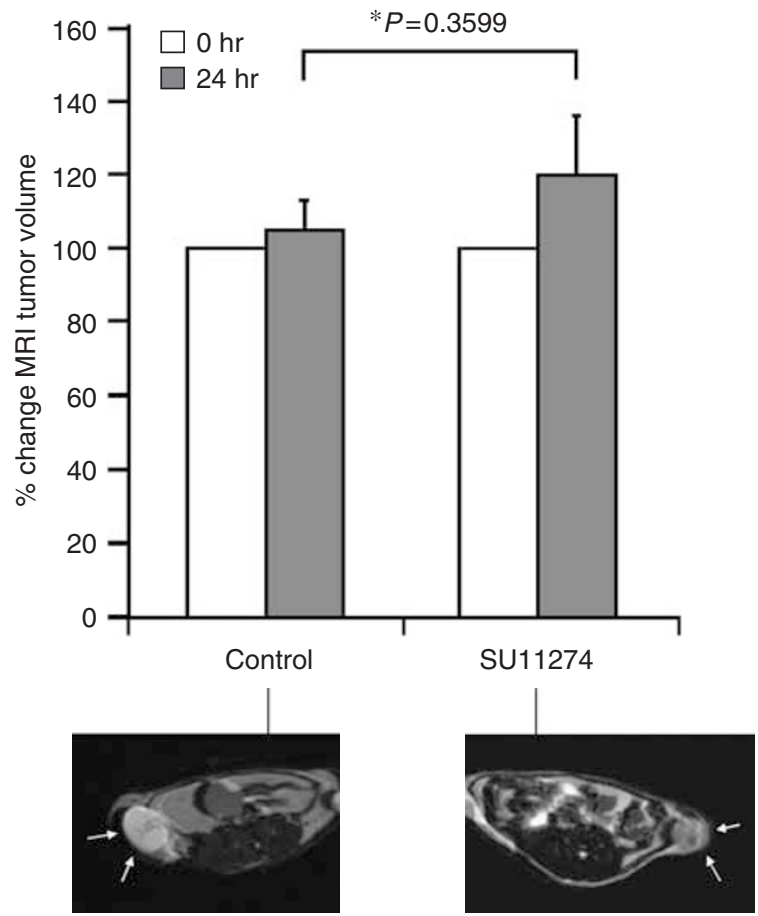

$\frac{\text { SU11274 }}{\text { PRE POST }}$

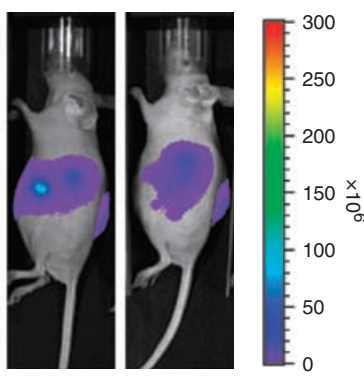

是$$
\text { (2) }
$$

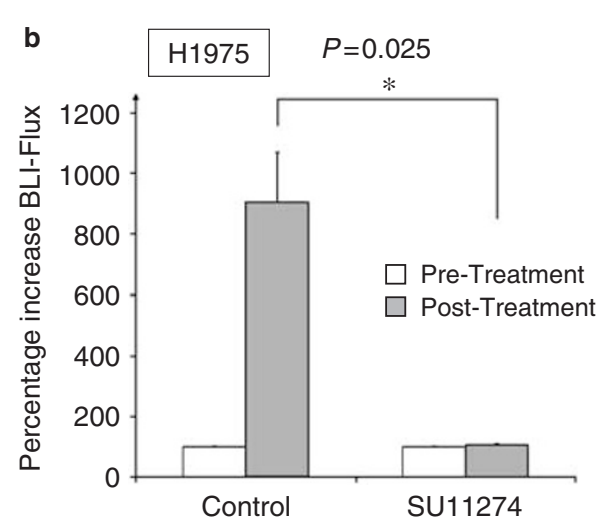

d

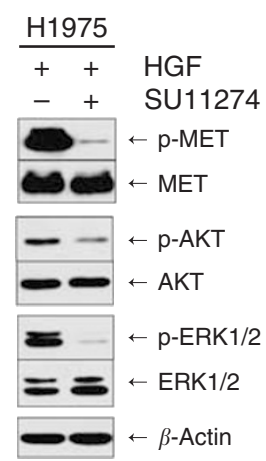

Figure 3 Continued.

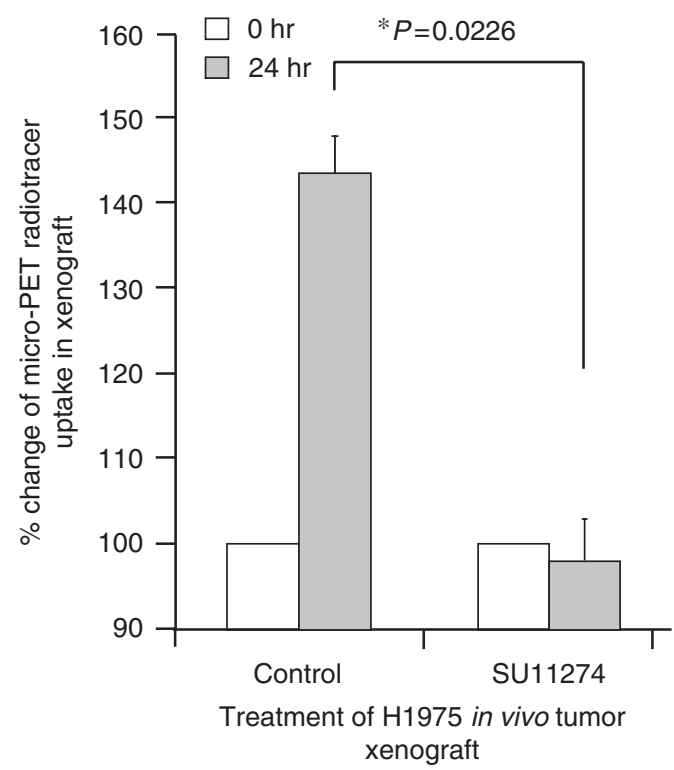

$$
\text { xenograft }
$$




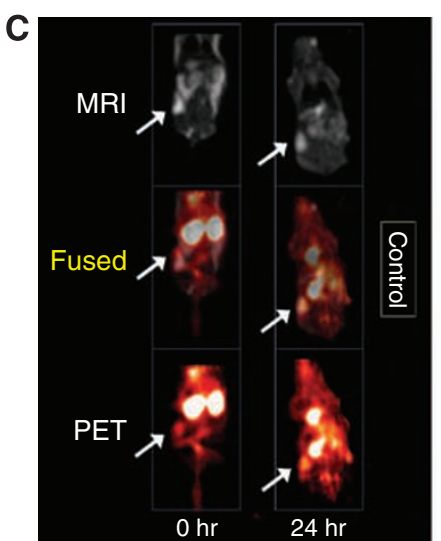

Control

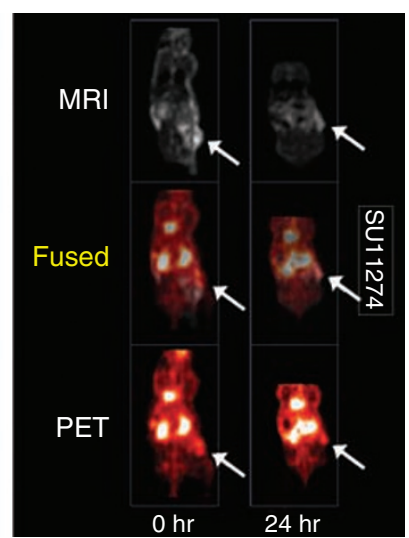

SU11274

Figure 3 MET inhibition with SUII274 successfully induced in vivo tumour response in EGFR-TKI-resistant HI975 cells in murine xenograft model assessed by multimodal molecular imaging. (A) In vivo tumour xenografts for H1975-luc cells were established as described in the Materials and Methods section in 6-week old nude mice. Daily SUI I 274 ( $100 \mu \mathrm{g}$ per xenograft) treatment was administered to the HI975-luc lung cancer tumour xenografts in nude mice as described. DMSO diluent control was included for comparison. Imaging was performed using a Xenogen IVIS 200 System cooled CCD camera at indicated times. (a) Representative BLI digital pictures of nude mouse from each of the treatment conditions are illustrated. SUI I 274 significantly inhibited L858R T790M-EGFR expressing HI975-luc in vivo tumorigenesis within the treatment durations ( 6 days). (b) Mean values of relative BLI flux of each group are plotted here (HI975-luc). N=4 per treatment group. Error bar, s.e.m. (*), $P=0.025$ for H1975-luc. Representative tumour xenograft micrographs from HI975-luc (c) cell line under haematoxylin and eosin (H\&E) staining are also shown here for the control and SUI I 274 treatment animals. Magnification $\times 100$ (inset, $\times 200$ ). (d) SUII 274 inhibited HGFdriven signalling activation in HI975 cells. HI975 cells were stimulated with HGF (50 ng ml ${ }^{-1}$, I $5 \mathrm{~min}$ ) and inhibited by MET inhibitor SUI I 274 ( I $\mu \mathrm{M}$, $4 \mathrm{~h}$ ) in vitro, and analysed with 7.5\% SDS-PAGE and immunoblotting with the indicated antibodies as described in Materials and Methods. (B, C Magnetic resonance imaging (MRI) and microPET molecular imaging studies of MET inhibition of HI975 in vivo xenograft. HI975 in vivo xenografts were established as above for treatment with either diluent control $(N=2)$ or SUII $274(N=2)$. The nude mice with HI975 xenografts were subjected to $\mathrm{MRI}$ and microPET imaging as described in the Materials and Methods section at 0 , and $24 \mathrm{~h}$ with the MET inhibitor SUI I 274 treatment or diluent control. (B) Examples of the transverse sections of high-resolution MRI images of the tumour xenografts at baseline between the two treatment groups were shown here for illustration (left). The MRI tumour volumes were analysed digitally with the calculated tumour volume changes at the indicated time intervals ( 0 and $24 \mathrm{~h}$ ) plotted. Comparing with baseline, the control xenograft tumour volume increased by $105.1 \pm 8.3 \%$ at $24 \mathrm{~h}$, whereas the SUI 1274-treated xenografts increased by $120.2 \pm 16.2 \%$ at $24 \mathrm{~h}$. The MRI tumour volumes changes at $24 \mathrm{~h}$ post-treatment between the two groups were not statistically significant $(* P=0.360)$. Error bar, s.e.m. Quantitative microPET radiotracer uptake of the HI975 tumour xenografts at $60 \mathrm{~min}$ of radiotracer tail-vein infusion in the animals' pretreatment baseline $(0 \mathrm{~h})$ and post-MET-TKI treatment at $24 \mathrm{~h}$ is shown graphically (right). $N=2$ in each treatment group: Control and SUII274. Error bar, s.e.m. Representative co-registered pictures of the microPET/MR (low-resolution) images of each xenograft from the two treatment groups are shown in (C). SUI 1274 induced early tumour metabolic response, as early as 24-h post-TKI treatment, with statistically significant inhibition of glucose metabolism as evident in the decrease in microPET uptake signal intensity by $45 \%(P=0.0226)$ in SUII274-treated xenografts, when compared with diluent control. The degree of increase in the glucose uptake in the HI975 tumour xenograft in diluent control is also consistent with the average rate of the xenograft growth (increase of $50.8 \%$ BLI flux per day) as reflected in the bioluminescence imaging.

cross-activation between the two receptors (Figure 4), we next investigated if MET inhibition could be enhanced in combination with an EGFR inhibitor. The EGFR-TKI-resistant H1975 cells were

tested against SU11274 inhibition, either alone or in combination with erlotinib. We determined the functional effect of combined MET-EGFR inhibition on the cytoskeletal functions of H1975 cells. Cell motility and migration are crucial cellular regulatory functions in tumour cell invasion and metastasis. Video microscopy studies showed that SU11274 inhibition substantially abrogated the constitutively activated cytoskeletal changes of the serum-starved H1975 cells (with activated p-MET and p-EGFR), as reflected in the cellular migrational trajectories and velocity (Supplementary Figure 3). Moreover, SU11274 alone had some inhibitory effect on cytoskeletal functions in H1975 cells under serum-stimulated (10\% FBS) conditions, whereas concurrent dual TKI combinatorial inhibition using SU11274 plus erlotinib completely abrogated the cytoskeletal functions (Figure 5A).

Using dual-ligand concurrent stimulation (HGF and EGF) to activate both MET and EGFR in A549 and H1975 cells, single TKI alone was relatively ineffective in inhibiting the downstream signalling completely (Figure 5B). On the other hand, concurrent dual inhibition with MET-EGFR TKIs (SU11274 plus erlotinib) effectively induced cooperative and enhanced inhibition of the key downstream proliferative/survival and anti-apoptotic signal paths (phospho-AKT, phospho-ERK1/2, and phospho-STAT3) (Figure 5B). Most interestingly, despite the fact that p-EGFR[Y1068] was not significantly inhibited under the dual SU11274/erlotinib combinatorial treatment in H1975 cells, p-ERBB3[Y1289] activation was effectively abrogated only under this dual inhibitory strategy (Figure 5B).

The signalling experiment using $M E T$-specific siRNA instead of SU11274 in A549 cells (Figure 5C) showed similar inhibition synergism using dual RTK inhibition with siRNA-MET and erlotinib. Using the A549 cell line as a model, we further demonstrated that alternative ligand-stimulated RTK signalling (MET-HGF and EGFR-EGF) indeed could rescue the downstream signalling activation from single targeted inhibitor (Figure 5D), supporting our hypothesis of the optimal efficacy of dual MET -EGFR inhibition especially in the in vivo setting where both RTK signal paths are functional and activated. Irreversible EGFR-TKIs (Kobayashi et al, 2005b), such as CL-387,785 or HKI-272 (Ruhe et al, 2007), have been shown to exhibit inhibitory efficacy against erlotinib-resistant T790M mutation. Here, in H1975 cells, results similar to erlotinib were obtained using the irreversible EGFR-TKI, CL-387,785, in combination with SU11274 (Figure 5E).

As erlotinib is the only FDA-approved clinical EGFR-targeted inhibitor for the treatment of advanced lung cancer in the United States, we further investigated its potential use in combination with MET inhibition against erlotinib-resistant H1975 cells using an in vitro cellular viability assay and BLI tumour xenograft growth assay in vivo. Under serum-stimulated conditions, when both EGFR and MET were basally activated, SU11274 plus erlotinib ( $3 \mu \mathrm{M}$ of each TKI) induced a significantly enhanced cell viability inhibition ( $3 \mu \mathrm{M}$ : $58.0 \pm 6.8 \%, P<0.05)$, when compared with either erlotinib or SU11274 treatment alone (Figure 6A). To further validate this combination dual TKI strategy, we also subjected the H1975 cells to pathway-specific siRNA knockdown of the MET and EGFR kinase signal paths, either alone or in combination, under serum-stimulated conditions (Figure 6B). Optimal downstream signalling inhibition (phospho-AKT and phospho-STAT3) and global phosphotyrosine ( $\mathrm{p}$-Tyr) cellular signalling inhibition were achieved through dual inhibition with siRNA knockdown of both $M E T$ and EGFR targets, when compared with single target knockdown. Taken together, these data provide support that cooperative enhanced inhibition using dual TKIs against MET and EGFR pathways may be an effective treatment strategy to inhibit lung cancer with intrinsic or acquired T790M-EGFR-mediated TKI resistance.

Finally, we also tested concurrent dual SU11274 plus erlotinib combinatorial treatment in our in vivo H1975-luc BLI xenograft 
A

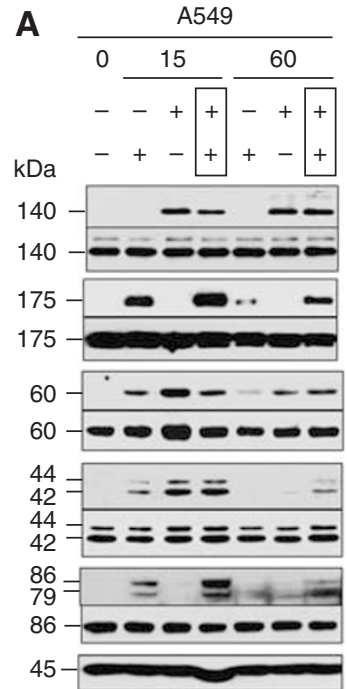

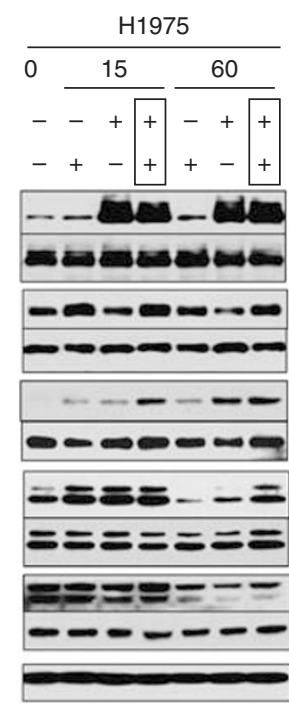

B

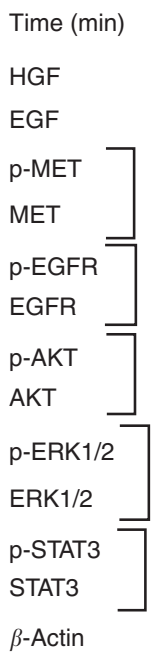

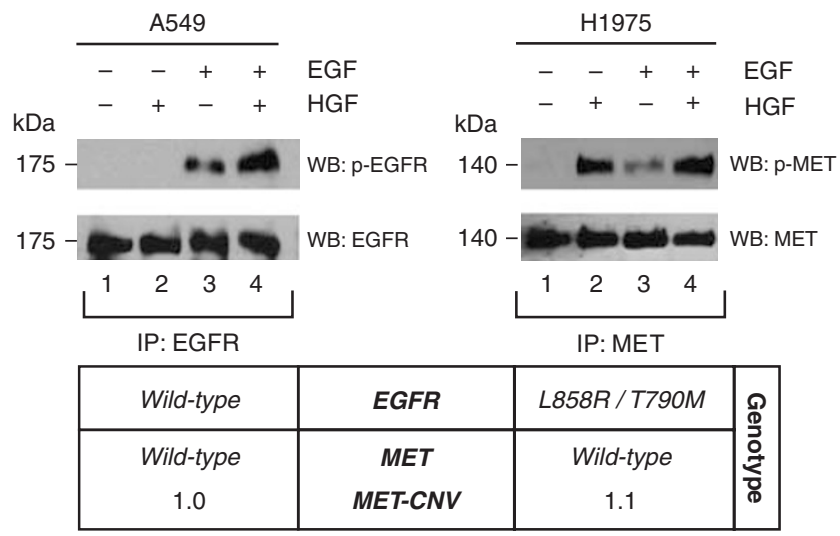

Figure 4 Signalling cross-activation between MET and EGFR signalling pathways. (A) Cross-activation between MET and EGFR signalling in lung cancer cells, A549 and H1975. A549 or HI975 cells were cultured in serum-starved conditions with exogenous stimulation with RTK ligands: EGF alone, HGF alone, or both EGF and HGF. Cells without any ligand stimulation were included as control. Both MET and EGFR signalling pathways are functional and ligand-sensitive in A549 and HI975 cells. There was augmented downstream signalling with combined EGF-HGF co-stimulation, with also more durable signalling induction. In A549 cells, although HGF alone did not activate EGFR phosphorylation appreciably, under co-stimulation conditions with EGF together, HGF further enhanced the EGFR phosphorylation in A549 cells to a level higher than that with EGF alone. On the other hand, EGF stimulation of HI975 cells co-activated MET receptor to enhance the level of MET phosphorylation. (B) MET-EGFR cross-activation in lung cancer. Left panel (A549), HGF cross-activated p-EGFR in A549 cells in the presence of co-stimulation with EGF. A549 cells were cultured in serum-starved conditions overnight, then stimulated with EGF alone ( $\left.100 \mathrm{ng} \mathrm{ml}^{-1}, 15 \mathrm{~min}\right)$, HGF alone $(50 \mathrm{ng} / \mathrm{ml}, 15 \mathrm{~min})$, or both. Whole cell lysates were collected for immunoprecipitation with EGFR antibody, followed by immunoblotting (WB) with antibodies against p-EGFR[YI068] (upper panel) and total EGFR (lower panel). Right panel (HI975), EGF cross-activates phospho-MET in HI975 cells. HI975 cells were cultured in starved media overnight, then stimulated with EGF alone $\left(100 \mathrm{ng} \mathrm{ml}^{-1}, 15 \mathrm{~min}\right), \mathrm{HGF}$ alone $\left(50 \mathrm{ng} \mathrm{ml}^{-1}, 15 \mathrm{~min}\right)$, or both. Whole cell lysates were collected for immunoprecipitation with MET antibody (C-12), followed by immunoblotting with antibodies against p-MET[Y I 234/I235] (upper panel) and total MET (lower panel). The MET and EGFR genotypes of the A549 and HI975 cells, as well as their MET genomic copy numbers, are shown in the bottom.

growth assay (Figure 6C). Here, a suboptimal daily dose of SU11274 (50 $\mu$ g per xenograft per day) was found to be partially effective in retarding the xenograft growth, when compared with either diluent control or erlotinib $\left(100 \mathrm{mg} \mathrm{kg}^{-1} \mathrm{day}^{-1}\right)$ alone. Moreover, we found that combining SU11274 with erlotinib induced a complete tumour xenograft regression (0.12-fold BLI from baseline), evident within 2 weeks of dual inhibitor therapy. The difference seen with dual MET-EGFR-TKIs treatment is statistically significant when compared with either erlotinib alone (35.8-fold BLI increase, $P=0.0006$ ) or with SU11274 alone (12.2fold, $P=0.0003)$. These molecular imaging data were confirmed by xenograft H\&E-stained histology examination (Figure 6D). In particular, the combined SU11274 plus erlotinib treatment resulted in substantial tumour necrosis.

\section{DISCUSSION}

At least half of the acquired resistance to EGFR-TKI in advanced NSCLC patients is thought to be mediated by the 'gatekeeper' mutation T790M in exon 20 of EGFR (Kobayashi et al, 2005a; Pao et al, 2005). Many tumours with intrinsic resistance to erlotinib/ gefitinib were found to have wild-type EGFR and/or mutant KRAS. At present, no FDA-approved inhibitor drugs have been shown to be successful in overcoming T790M-mediated resistance clinically. Recent study suggested that T790M-EGFR-mediated resistance could even emerge from the irreversible EGFR/ERBB2 inhibitor HKI-272 treatment at maximally tolerated dosing, as it mediates resistance to low concentrations of the irreversible inhibitor (Godin-Heymann et al, 2008). Alternative novel therapies to target lung cancer patients with intrinsic or acquired resistance to erlotinib are needed. MET has recently been affirmed to be an attractive anti-neoplastic therapeutic target (Corso et al, 2005;
Peruzzi and Bottaro, 2006; Salgia, 2006), including lung cancer (Christensen et al, 2003, 2005; Ma et al, 2003a, b, 2005a, b; Sattler et al, 2003). MET was found overexpressed in up to $67 \%$ of lung adenocarcinomas in our previous study ( $\mathrm{Ma}$ et al, 2005a). Various targeted inhibitory strategies are being undertaken in drug development to antagonise MET/HGF signalling in human cancers, including small-molecule kinase inhibitors, antibodies to the ligand HGF, and receptor MET itself (Christensen et al, 2005; Martens et al, 2006; Peruzzi and Bottaro, 2006). In this study, we identified that there is frequent co-expression of MET and EGFR in NSCLC cell lines. In the erlotinib-resistant H1975 cell line (L858R/T7980M-EGFR), MET is neither genomically amplified nor mutated. Yet, MET is activated in the cells, possessing both constitutive (serum/ligand-independent) and basal (serum-stimulated) receptor activation. Furthermore, MET also remains HGF ligand-sensitive. Owing to the unique intrinsic properties of MET regulating cellular 'invasive signalling', MET has been proposed as not merely playing a role in 'oncogene addiction' in a small subset of human cancers but can also play an essential role in 'oncogene expedience' by inducing an enhanced transformed tumour malignant 'fitness' in a much larger range of cancers leading to promotion of tumour progression (Comoglio et al, 2008). And in the latter case, activated MET can intercept with various other oncogenic signals, including mutant-EGFR, in maintaining and enhancing the tumour invasive-progressive phenotype, thereby also allowing the opportunity for MET to be a therapeutic target even in late advanced metastatic disease. The MET inhibitor SU11274 was shown to promote apoptosis in H1975 cells, but was ineffective in the MET-negative/EGFR-negative H520 cells. SU11274 was previously characterised to be a selective, reversible ATP-competitive inhibitor of MET kinase (Sattler et al, 2003; Ma et al, 2005a). Here, we show that SU11274 exhibited inhibitory efficacy in the EGFR-TKI-resistant H1975 cells both in vitro and 

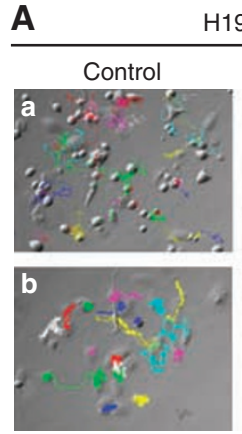

Erlotinib SU11274 + Erlotinib

C

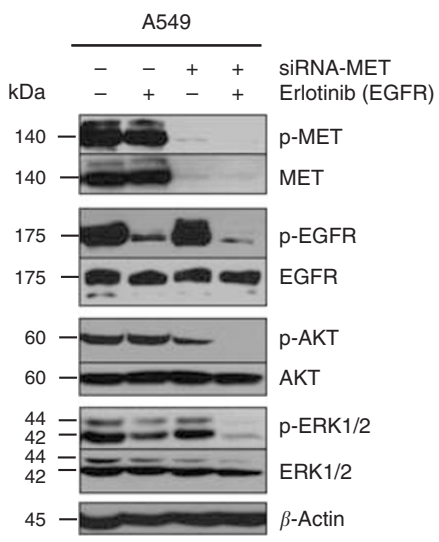

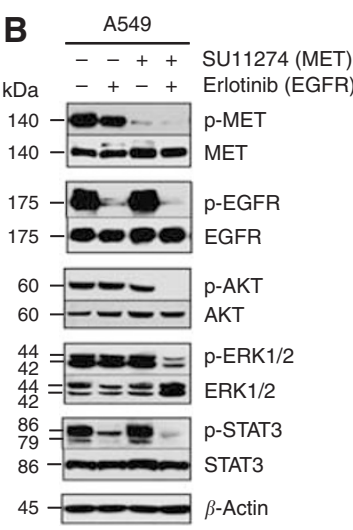

D

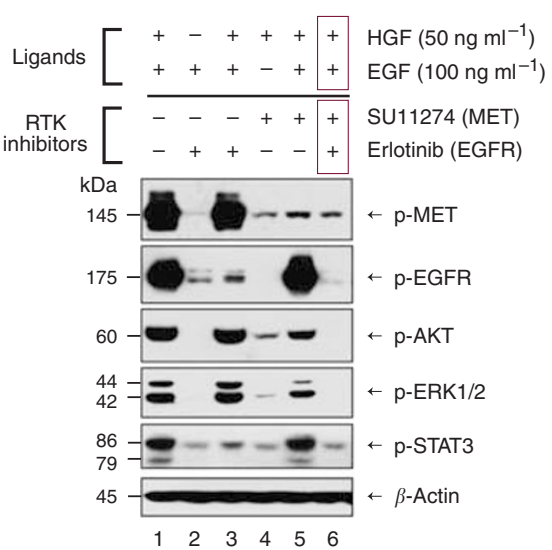

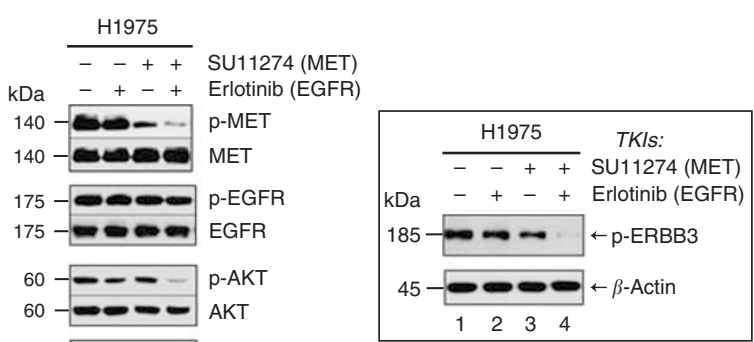

${ }_{42}^{44}==-ー$ p-ERK $1 / 2$

42 ニテことニ ERK $1 / 2$

$86-\ldots$ p-STAT3

$86-2$ STAT3

$45-\infty$-Actin

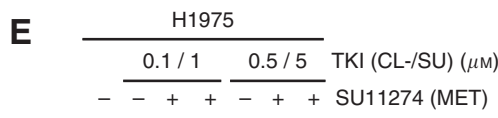

$\mathrm{kDa} \quad+-++-+$ CL-387,785 (EGFR)

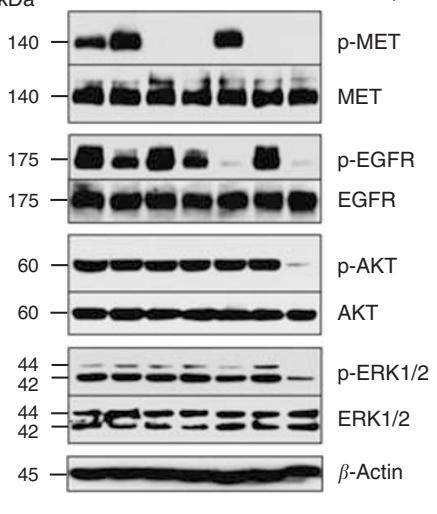

Figure 5 SUI 274 inhibition of MET in combination with EGFR inhibitor in erlotinib-resistant NSCLC cell signalling. (A) Potentiated inhibition of cellular cytoskeletal functions by combined MET-EGFR inhibition (SUI I 274 plus erlotinib) in HI 975 cells under video microscopy. HI 975 cells had constitutively activated cytoskeletal functions with enhanced cell motility and migration under the serum-starved culture conditions. Comparing with the untreated control (left panel), drug treatment using SUII274 (right panel) substantially inhibited the constitutively activated cytoskeletal functions of HI975 cells (Supplementary Figure 3). HI975 cells were cultured in serum-stimulated conditions (I0\% FBS) and treated with the following for video microscopy digital video recording as described in the Materials and Methods: (a) DMSO diluent control, (b) Erlotinib alone (2 $\mu \mathrm{M}$ ), (c) SUI I 275 alone (5 $\mu \mathrm{M}$ ), and (d) combined concurrent SUI I $274(5 \mu \mathrm{M})$ + erlotinib $(2 \mu \mathrm{M})$. Complete abrogation of cytoskeletal functions with inhibition of cell motility and migration was only evident in the dual SUI I274/erlotinib TKI-treated cells (d). (B) MET inhibition using SUI I 274, in combination with EGFR inhibition (erlotinib), induced cooperative downstream signalling inhibition in A549 (left panel) and HI975 (right panel) cells in vitro. EGFR-TKI-resistant A549 and HI975 cells were cultured in serum-starved conditions with EGF and HGF dual ligands stimulation as described in the Materials and Methods section. The cells were treated with SUI I 274 alone, erlotinib alone, or combination SUI I 274 plus erlotinib, then analysed in immunoblotting as indicated. (C) MET inhibition using specific siRNA-MET, in combination with EGFR inhibition (erlotinib) induced cooperative downstream signalling inhibition in A549 cells in vitro. Cells were transfected with control siRNA or siRNA-MET as described in Methods. Forty-eight hours after transfection, cells were cultured in starved media overnight, then treated with or without erlotinib and alone or in combination with siRNA-MET as indicated. After $4 \mathrm{~h}$ of inhibitor treatment, cells were then stimulated with both EGF $\left(100 \mathrm{ng} \mathrm{ml}^{-1}\right)$ and HGF $\left(50 \mathrm{ng} \mathrm{ml}^{-1}\right)$ ligands as indicated for $15 \mathrm{~min}$. Whole cell lysates were then collected for immunoblotting analysis as in panel B above. (D) Rescue from alternative RTK ligand-stimulated signalling (MET-HGF vs EGFR-EGF) against TKI in A549 cells. A549 cells were cultured under serum-starved conditions, and then treated with either HGF or EGF, and in the presence or absence of the corresponding targeted inhibitor SUI I 274 or erlotinib as indicated (lanes 2,4). Dual ligand stimulation (HGF and EGF) with single or dual TKls treatment was included as indicated (lanes I, 3, 5, 6). Although receptor-specific TKI was able to inhibit the downstream signalling driven by the corresponding ligand stimulation, alternative ligand stimulation in the form of dual ligand stimulation rescued the inhibited downstream signals. Dual TKI SUI I 274 plus erlotinib inhibition was required to fully knockdown the dual ligand-stimulated downstream signal activation of AKT, ERKI/2, and STAT3 (lane 6). (E) MET inhibition with SUI I 274, in combination with EGFR inhibition using CL-387,785 (irreversible EGFR-TKI), induced cooperative downstream signalling inhibition in HI975 cells in vitro. Cells were cultured in starved media overnight, then treated with or without CL-387,785 and alone or in combination with MET inhibitor SUII274 as indicated. After 4h of inhibitor treatment, cells were then stimulated with both EGF $\left(100 \mathrm{ng} \mathrm{ml}^{-1}\right)$ and HGF $\left(50 \mathrm{ng} \mathrm{ml}^{-1}\right)$ ligands as indicated for 15 min. Whole cell lysates were then collected for immunoblotting analysis. Similar to erlotinib, CL-387,785 further sensitised HI 975 cells to SUI I 274 inhibition with enhanced cooperative inhibition of signalling pathways downstream of the two RTKs.

in vivo. In particular, it inhibited MET signalling, induced cellular apoptosis, and abrogated cytoskeletal functions (key controlling step in tumour invasion and metastasis) in vitro (Birchmeier et al, 2003), and was effective in vivo, leading to cytoreduction of murine tumour xenografts of the T790M-EGFR expressing erlotinibresistant H1975 cells. Taken together, our study supports the hypothesis that MET may be targeted to circumvent T790M-EGFRmediated intrinsic or acquired resistance to EGFR-TKI (erlotinib) in lung cancer.

H1975 cells were tested further to provide a better understanding of the mechanism of dual MET - EGFR inhibition. A549 cell line was included as model in signalling studies for comparison with H1975 


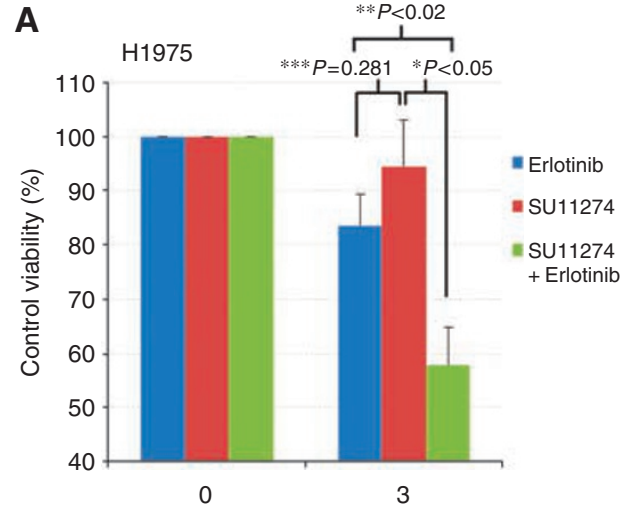

Tyrosine kinase inhibitor, conc. $(\mu \mathrm{M})$
B

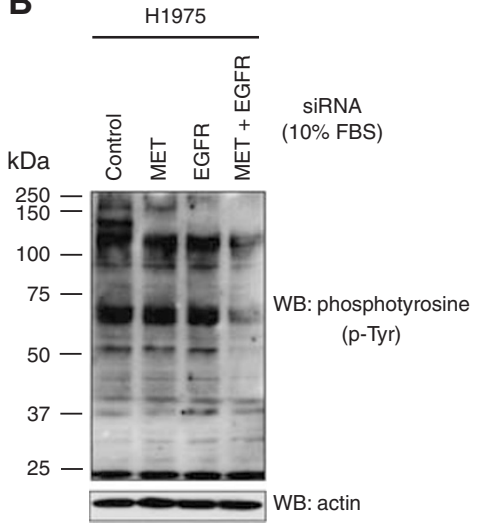

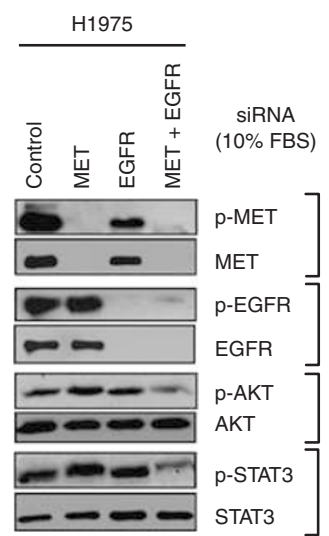

H1975 xenograft
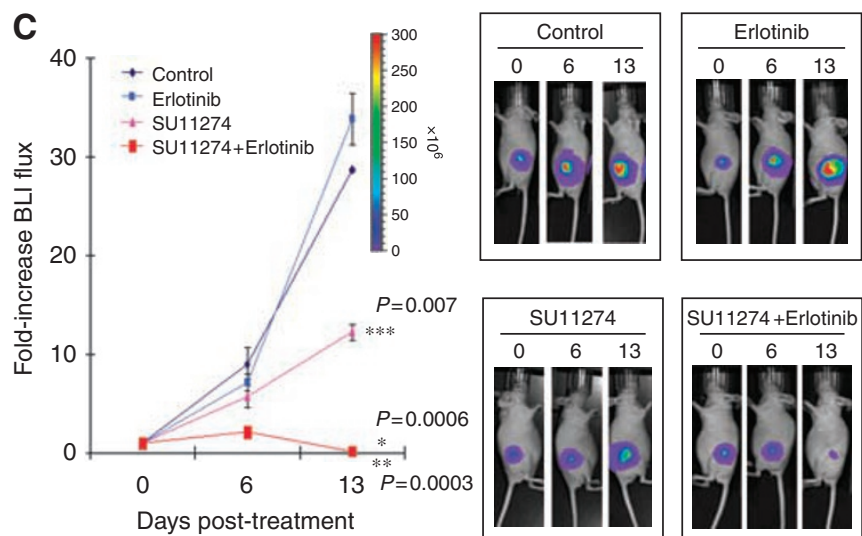

D
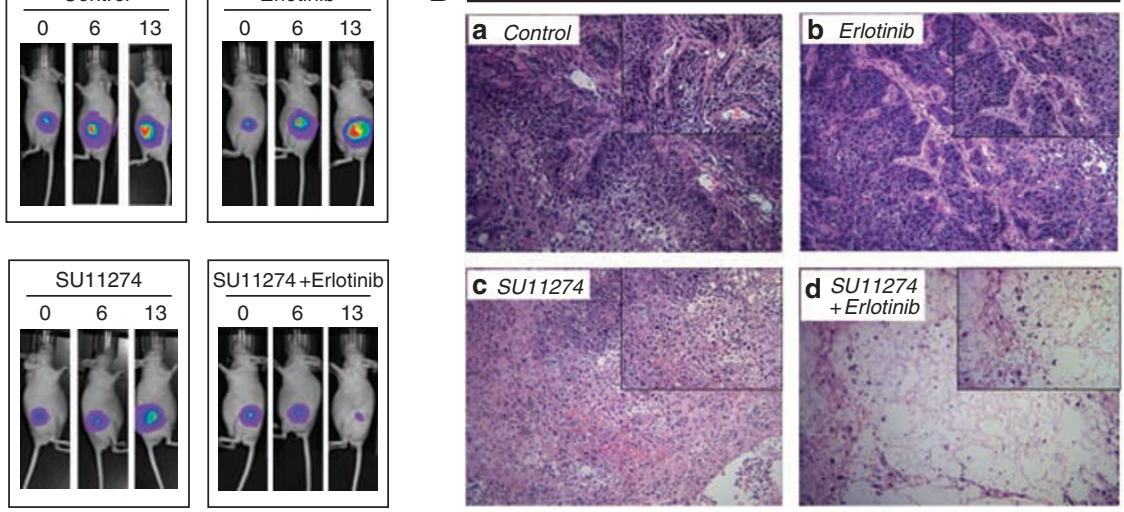

Figure 6 Dual SUI 1274-erlotinib inhibition induced cooperative inhibition in HI975 cell viability in vitro and murine xenograft tumour growth in vivo. (A)

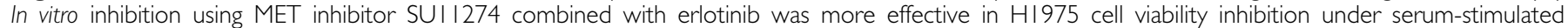

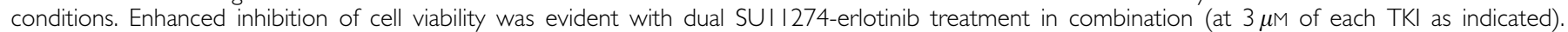

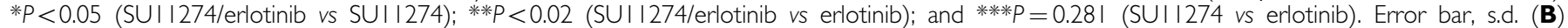

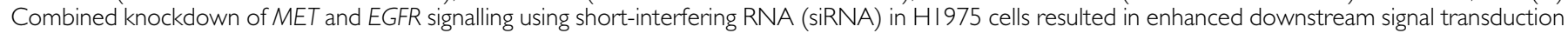

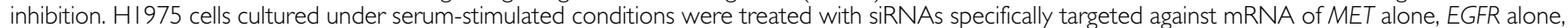

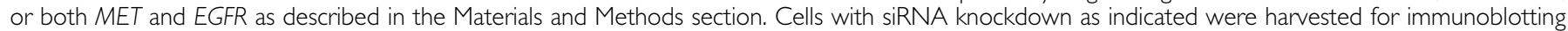

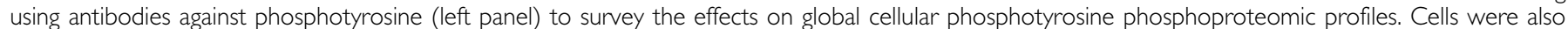

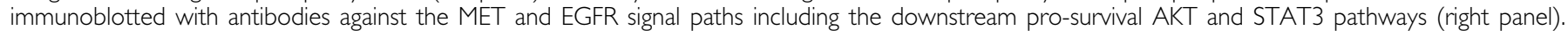

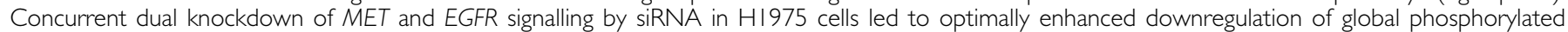

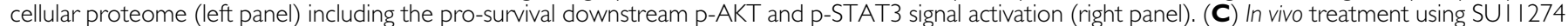

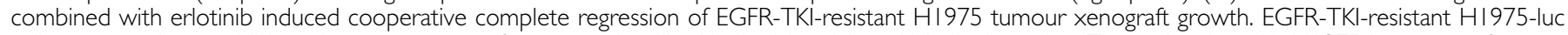

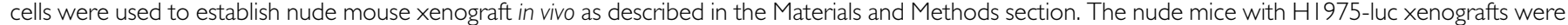

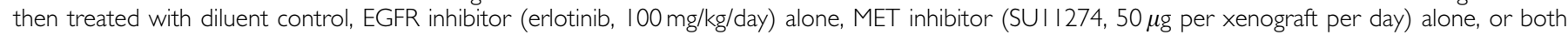

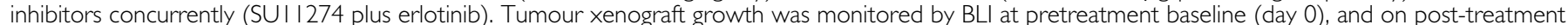

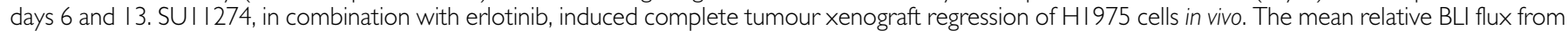

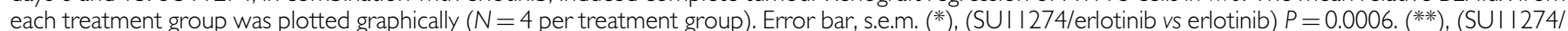

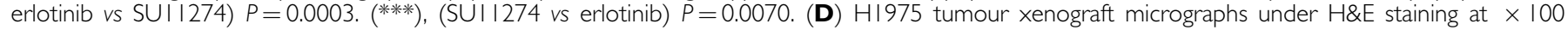

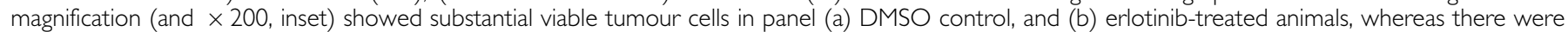

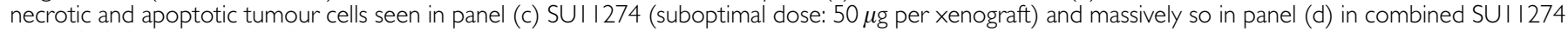
plus erlotinib-treated animals.

cells. A549 is an extensively studied lung cancer cell line and is known to have KRAS mutation but not any EGFR kinase domain mutations. In our in vitro signalling studies, we identified that there was signalling cross-activation between MET and EGFR in both A549 and H1975 cells. Nonetheless, the pattern of cross-activation appeared to be different between the two cell lines. In A549 cells, HGF brought about cooperative induction of p-EGFR[Y1068] in the presence of EGF, whereas in H1975 cells, EGF induced crossactivation of p-MET[Y1234/1235] by itself and further MET activation when combined with HGF in dual ligand stimulation. It is tempting to postulate that the different pattern of crossactivation observed in A549 and H1975 cells might be a result of the different EGFR kinase mutational status in the two cell lines, that is non-mutated in A549 but L858R/T790M in H1975. The mutant EGFR in H1975 evidently is capable of cross-activating MET in an EGF - ligand-dependent manner, indicating that MET could be 'downstream' of the mutant EGFR in H1975. Of interest, it has recently been shown that the MET receptor activating phosphorylation site was highly responsive to EGFRvIII levels in glioblastoma cells in vitro, suggesting downstream cross-activation of MET by mutant EGFRvIII (Huang et al, 2007).

L858R/T790M-EGFR mutations exist in $\mathrm{H} 1975$ cells in-cis (Pao et al, 2005). The double mutations not only confer resistance to gefitinib/erlotinib but also result in markedly enhanced catalytic kinase and oncogenic activity (Mulloy et al, 2007). Emerging evidence suggests that the T790M 'gatekeeper' mutation may exist 
in lung tumours before EGFR-TKI therapeutic selection (Bell et al, 2005; Godin-Heymann et al, 2007), partly due to its enhanced oncogenicity, and accounts for the adverse clinical course and outcome in gefitinib/erlotinib-resistance lung cancers after a course of rapid TKI selection. Interestingly, we found that H1975 cells co-express EGFR and MET at high level, although without any $M E T$ genomic amplification, and were capable of serum-independent constitutive MET activation. Moreover, MET and EGFR engage in collaborative signalling cross-activation to transduce stronger and more durable downstream signals. A recent report utilised a mutant EGFR (deletion 19)-expressing NSCLC cell line HCC827, which is highly sensitive to gefitinib, an in vitro gefitinib-resistance long-term inhibition culture system to select for gefitinib-resistant cell subclones (Engelman et al, 2007). Acquired MET amplification was identified to be a potential alternative mechanism to enable the mutant EGFR-expressing HCC827 to become secondarily resistant (HCC827-GR) without a T790M mutation. In the course of our study, Bean et al (2007) reported the presence of $M E T$ amplification that occurred independently with and without T790M-EGFR mutation in lung tumours. MET amplification in gastric cancer cell lines has recently been correlated with high sensitivity towards MET inhibitor (Smolen et al, 2006). Interestingly, another recent report adopted a global phosphoproteomic approach using cell lines sensitive to gefitinib (HCC827) and sensitive to SU11274 (MKN45), and showed that besides p-EGFR inhibition, gefitinib also inhibited p-MET (that is indeed constitutively activated) in HCC827, but not vice versa (Guo et al, 2008). In the case of SU11274, the MET inhibitor inhibited p-EGFR in MKN45 besides p-MET, but not vice versa (Guo et al, 2008). Further studies to examine the signalling cross-talk between the EGFR and MET receptor pathways in the context of mutations and downstream signalling networking would be helpful in optimising combinational therapeutic strategies. Moreover, it would be useful to further investigate and catalogue the activating mechanisms of $M E T$ (such as activating mutations, transcriptional and protein overexpression), and their role in oncogenic signalling in the context of multiple receptor co-activation in lung cancer.

Our report here demonstrates the efficacy of dual RTK targeted inhibition against MET (SU11274) and EGFR (erlotinib or CL-387,785) as a strategy to achieve optimised inhibition of cytoskeletal functions, cell viability, cellular signalling, and in vivo xenograft complete regression in T790M-EGFR-mediated erlotinib resistance. The concentrations of SU11274 used in our current study are consistent with previous results to be within the range of selectivity towards MET (Sattler et al, 2003; Ma et al, 2005a). Finally, our dual siRNA knockdown experiment against $M E T$ and EGFR (Figure 6B) in H1975 cells provides further validation of this novel therapeutic approach. Dual inhibition may be of benefit over single target inhibition, especially in the context of serum and/or alternative ligand stimulation. This can be of clinical relevance considering that tumour cells often exist and adapt in vivo under a multitude of host stromal conditions during various stages of tumour progression, including serum starvation (e.g. in tumour core), serum-stimulation, and also potentially microenvironmentspecific ligand(s)-stimulation.

Dual TKI combinatorial approach may allow more effective target inhibition with a lower MET inhibitor concentration requirement, when compared with monotherapy alone, as suggested in our in vivo H1975-luc xenograft study. The ability to use lower drug concentrations than that in monotherapy would be beneficial and clinically relevant to minimise additive toxicity profiles of two inhibitor drugs of similar class used in combination. It is intriguing that we consistently observed a modest, but readily detectable degree of potentiated inhibition of MET phosphorylation by erlotinib, with and without SU11274, both in A549 and in H1975 cells. In addition, our siRNA-EGFR knockdown study in H1975 cells resulted in appreciable downregulation of p-MET[Y1234/1235], suggesting that the mutant EGFR in H1975 cells might signal into MET as a 'downstream' cross-talk collaborative signal partner (Figure 6B). It may account for some of the enhanced inhibitory effects seen in the dual TKI treatment. In our in vivo bioluminescence xenograft model, combined SU11274-erlotinib inhibition remarkably induced complete H1975-luc tumour xenograft regression associated with histological features of massive tumour necrosis-apoptosis. We were initially intrigued that despite the lack of effective inhibition of EGFR phosphorylation (at pY1068) by erlotinib alone, the drug enhanced inhibitory efficacy both in vitro and in vivo in $\mathrm{H} 1975$ cells when combined with SU11274. Engelman et al (2007) recently reported that $M E T$, when amplified genomically as in the setting of acquired EGFR-TKI resistance, can capture the ERBB3 signal control from EGFR. Our data here suggest that MET inhibition (SU11274) in H1975 cells had a modest but detectible negative effect on ERBB3 activation, and that dual SU11274/erlotinib inhibition cooperatively abrogated p-ERBB3 signal activation completely (Figure 5B). This might partially explain the observed role of erlotinib in the dual inhibitory strategy against the T790M-EGFR mutant cells, even though it is ineffective against p-EGFR itself. Further studies to dissect the interplay between MET and ERBB3 signal paths in lung cancer are warranted. Besides the possible effect of erlotinib upon MET activation per se, one might not rule out other potential off-target effects of erlotinib as contributing factors. Stegmaier et al (2005) first reported a previously unrecognised EGFR-independent mechanism of gefitinib in inducing the differentiation and inhibiting proliferation of EGFR-negative acute myeloid leukaemia cells at clinically achievable doses (Stegmaier et al, 2005). More recently, erlotinib was also found to exhibit off-target antineoplastic effects in acute myeloid leukaemia and myelodysplastic syndrome, supporting the potential clinical therapeutic utility of these EGFR-TKIs in haematologic malignancies (Boehrer et al, 2007). As erlotinib is currently the only clinically approved EGFRTKI for lung cancer in the United States, discovery of its utility in combinatorial inhibitory approaches would be of potential clinical benefit. Combination strategy to target EGFR and MET has recently been reported to show promise in overcoming mutant-EGFRvIII-driven glioblastoma, although using a higher concentration range of MET inhibitor (Huang et al, 2007). Some success to overcome T790M-mutant EGFR resistance has been reported using irreversible EGFR/ERBB family inhibitors, such as CL-387,785 and HKI-272 (Kobayashi et al, 2005b; Wong, 2007). Nonetheless, recent work in a L858R/T790M-EGFR transgenic mouse model suggests that the double mutant-EGFR responds only partially to HKI-272 alone (Li et al, 2007), and enhanced inhibition was seen in combination with mammalian target of rapamycin inhibitor.

In conclusion, the present study identified that despite having no genomic MET alterations in H1975 cells, the MET-HGF signal path is functional and activated in this EGFR-TKI-resistant cell line that already expresses the oncogenic mutant EGFR (L858R/T790M) signal axis. There are also receptor cross-activation and signalling circuitry cross-talk between MET and EGFR, and MET inhibition has efficacy in vitro and in vivo in the erlotinib-resistant H1975 cells. Our results also implicate that combination treatment using a MET inhibitor plus a reversible or irreversible EGFR kinase inhibitor to achieve dual MET - EGFR inhibition may represent an alternative strategy to circumvent T790M-EGFR-mediated resistance in lung cancer. Importantly, erlotinib may still have clinical utility in this context of combined inhibition with MET inhibitor in EGFR-TKI-resistant lung cancer. As T790M-EGFR may play a role in both intrinsic and acquired EGFR-TKI resistance in lung cancer, it would be useful to test concurrent combinatorial METEGFR inhibitors in clinical trials on lung cancer patients refractory to erlotinib/gefitinib. Other emerging pan-ERBB class inhibitors, such as PF00299804, or EGFR-targeting dual/multitargeted 
inhibitors, such as lapatinib (EGFR/ERBB2 inhibitor) or ZD6474 (EGFR/VEGFR2 inhibitor), might also be candidates for combination with MET inhibitors. Whether a combined MET-EGFR inhibitory strategy as upfront treatment is superior to MET inhibition used only after EGFR-TKI monotherapy failure should be the subject of further investigation.

\section{ACKNOWLEDGEMENTS}

This work was supported by NIH/National Cancer Institute-K08 Mentored Career Development Award (1K08CA102545-01A2), Ohio Cancer Research Associates 'Give New Ideas A Chance'
Grant Award (both to PC Ma), NIH HL075422 and VA Merit Award (both to JA Kern), the Case Comprehensive Cancer Center (Genotype and Gene Expression Core, Confocal Microscopy Core, Xenograft and Athymic Animal Core, and Animal Imaging Core Facilities) of CWRU/University Hospitals Case Medical Center (P30 CA43703-12), and Northern-East Ohio Small Animal Imaging Resource Program (R24 CA110943). We also thank Drs Sanford Markowitz and David Danielpour (Case Western Reserve University) for helpful discussions.

Supplementary Information accompanies the paper on British Journal of Cancer website (http://www.nature.com/bjc)

\section{REFERENCES}

Bean J, Brennan C, Shih JY, Riely G, Viale A, Wang L, Chitale D, Motoi N, Szoke J, Broderick S, Balak M, Chang WC, Yu CJ, Gazdar A, Pass H, Rusch V, Gerald W, Huang SF, Yang PC, Miller V, Ladanyi M, Yang CH, Pao W (2007) MET amplification occurs with or without T790M mutations in EGFR mutant lung tumors with acquired resistance to gefitinib or erlotinib. Proc Natl Acad Sci USA 104: $20932-20937$

Bell DW, Gore I, Okimoto RA, Godin-Heymann N, Sordella R, Mulloy R, Sharma SV, Brannigan BW, Mohapatra G, Settleman J, Haber DA (2005) Inherited susceptibility to lung cancer may be associated with the T790M drug resistance mutation in EGFR. Nat Genet 37: 1315-1316

Benvenuti S, Comoglio PM (2007) The MET receptor tyrosine kinase in invasion and metastasis. J Cell Physiol 213: 316-325

Birchmeier C, Birchmeier W, Gherardi E, Vande Woude GF (2003) Met, metastasis, motility and more. Nat Rev Mol Cell Biol 4: 915-925

Boehrer S, Ades L, Braun T, Galluzzi L, Grosjean J, Fabre C, Le Roux G, Gardin C, Martin A, de Botton S, Fenaux P, Kroemer G (2007) Erlotinib exhibits anti-neoplastic off-target effects in AML and MDS: a preclinical study. Blood 111(4): 2170-2180

Choong NW, Dietrich S, Seiwert TY, Tretiakova MS, Nallasura V, Davies GC, Lipkowitz S, Husain AN, Salgia R, Ma PC (2006) Gefitinib response of erlotinib-refractory lung cancer involving meninges - role of EGFR mutation. Nat Clin Pract Oncol 3: 50-57; quiz 1 p following 57

Choong NW, Ma PC, Salgia R (2005) Therapeutic targeting of receptor tyrosine kinases in lung cancer. Expert Opin Ther Targets 9: 533-559

Christensen JG, Burrows J, Salgia R (2005) c-Met as a target for human cancer and characterization of inhibitors for therapeutic intervention. Cancer Lett 225: 1-26

Christensen JG, Schreck R, Burrows J, Kuruganti P, Chan E, Le P, Chen J, Wang X, Ruslim L, Blake R, Lipson KE, Ramphal J, Do S, Cui JJ, Cherrington JM, Mendel DB (2003) A selective small molecule inhibitor of c-Met kinase inhibits c-Met-dependent phenotypes in vitro and exhibits cytoreductive antitumor activity in vivo. Cancer Res 63: $7345-7355$

Comoglio PM, Giordano S, Trusolino L (2008) Drug development of MET inhibitors: targeting oncogene addiction and expedience. Nat Rev Drug Discov 7: $504-516$

Corso S, Comoglio PM, Giordano S (2005) Cancer therapy: can the challenge be MET? Trends Mol Med 11: 284-292

Dietrich S, Uppalapati R, Seiwert TY, Ma PC (2005) Role of c-MET in upper aerodigestive malignancies - from biology to novel therapies. J Environ Pathol Toxicol Oncol 24: 149-162

Engelman JA, Zejnullahu K, Mitsudomi T, Song Y, Hyland C, Park JO, Lindeman N, Gale CM, Zhao X, Christensen J, Kosaka T, Holmes AJ, Rogers AM, Cappuzzo F, Mok T, Lee C, Johnson BE, Cantley LC, Janne PA (2007) MET amplification leads to gefitinib resistance in lung cancer by activating ERBB3 signaling. Science 316: 1039-1043

Garcia S, Dales JP, Jacquemier J, Charafe-Jauffret E, Birnbaum D, AndracMeyer L, Lavaut MN, Allasia C, Carpentier-Meunier S, Bonnier P, Charpin-Taranger C (2007) c-Met overexpression in inflammatory breast carcinomas: automated quantification on tissue microarrays. $\mathrm{Br}$ J Cancer 96: $329-335$

Godin-Heymann N, Bryant I, Rivera MN, Ulkus L, Bell DW, Riese II DJ, Settleman J, Haber DA (2007) Oncogenic activity of epidermal growth factor receptor kinase mutant alleles is enhanced by the T790M drug resistance mutation. Cancer Res 67: 7319-7326

Godin-Heymann N, Ulkus L, Brannigan BW, McDermott U, Lamb J, Maheswaran S, Settleman J, Haber DA (2008) The T790M 'gatekeeper' mutation in EGFR mediates resistance to low concentrations of an irreversible EGFR inhibitor. Mol Cancer Ther 7: 874-879

Guo A, Villen J, Kornhauser J, Lee KA, Stokes MP, Rikova K, Possemato A, Nardone J, Innocenti G, Wetzel R, Wang Y, MacNeill J, Mitchell J, Gygi SP, Rush J, Polakiewicz RD, Comb MJ (2008) Signaling networks assembled by oncogenic EGFR and c-Met. Proc Natl Acad Sci USA 105: 692-697

Huang PH, Mukasa A, Bonavia R, Flynn RA, Brewer ZE, Cavenee WK, Furnari FB, White FM (2007) Quantitative analysis of EGFRvIII cellular signaling networks reveals a combinatorial therapeutic strategy for glioblastoma. Proc Natl Acad Sci USA 104: 12867 - 12872

Kobayashi S, Boggon TJ, Dayaram T, Janne PA, Kocher O, Meyerson M, Johnson BE, Eck MJ, Tenen DG, Halmos B (2005a) EGFR mutation and resistance of non-small-cell lung cancer to gefitinib. $N$ Engl J Med 352: $786-792$

Kobayashi S, Ji H, Yuza Y, Meyerson M, Wong KK, Tenen DG, Halmos B (2005b) An alternative inhibitor overcomes resistance caused by a mutation of the epidermal growth factor receptor. Cancer Res 65: 7096-7101

Li D, Shimamura T, Ji H, Chen L, Haringsma HJ, McNamara K, Liang MC, Perera SA, Zaghlul S, Borgman CL, Kubo S, Takahashi M, Sun Y, Chirieac LR, Padera RF, Lindeman NI, Janne PA, Thomas RK, Meyerson ML, Eck MJ, Engelman JA, Shapiro GI, Wong KK (2007) Bronchial and peripheral murine lung carcinomas induced by T790M-L858R mutant EGFR respond to HKI-272 and rapamycin combination therapy. Cancer Cell 12: $81-93$

Lynch TJ, Adjei AA, Bunn Jr PA, Eisen TG, Engelman J, Goss GD, Haber DA, Heymach JV, Janne PA, Johnson BE, Johnson DH, Lilenbaum RC, Meyerson M, Sandler AB, Sequist LV, Settleman J, Wong KK, Hart CS (2006) Summary statement: novel agents in the treatment of lung cancer: advances in epidermal growth factor receptor-targeted agents. Clin Cancer Res 12: 4365s-4371s

Ma PC, Jagadeeswaran R, Jagadeesh S, Tretiakova MS, Nallasura V, Fox EA, Hansen M, Schaefer E, Naoki K, Lader A, Richards W, Sugarbaker D, Husain AN, Christensen JG, Salgia R (2005a) Functional expression and mutations of c-Met and its therapeutic inhibition with SU11274 and small interfering RNA in non-small cell lung cancer. Cancer Res 65: $1479-1488$

Ma PC, Kijima T, Maulik G, Fox EA, Sattler M, Griffin JD, Johnson BE, Salgia R (2003a) c-MET mutational analysis in small cell lung cancer: novel juxtamembrane domain mutations regulating cytoskeletal functions. Cancer Res 63: 6272-6281

Ma PC, Maulik G, Christensen J, Salgia R (2003b) c-Met: structure, functions and potential for therapeutic inhibition. Cancer Metastasis Rev 22: $309-325$

Ma PC, Schaefer E, Christensen JG, Salgia R (2005b) A selective small molecule c-MET Inhibitor, PHA665752, cooperates with rapamycin. Clin Cancer Res 11: 2312-2319

Martens T, Schmidt NO, Eckerich C, Fillbrandt R, Merchant M, Schwall R, Westphal M, Lamszus K (2006) A novel one-armed anti-c-Met antibody inhibits glioblastoma growth in vivo. Clin Cancer Res 12: 6144-6152 
Maulik G, Kijima T, Ma PC, Ghosh SK, Lin J, Shapiro GI, Schaefer E, Tibaldi E, Johnson BE, Salgia R (2002) Modulation of the c-Met/hepatocyte growth factor pathway in small cell lung cancer. Clin Cancer Res 8: $620-627$

Miyata Y, Kanetake H, Kanda S (2006) Presence of phosphorylated hepatocyte growth factor receptor/c-Met is associated with tumor progression and survival in patients with conventional renal cell carcinoma. Clin Cancer Res 12: 4876-4881

Mulloy R, Ferrand A, Kim Y, Sordella R, Bell DW, Haber DA, Anderson KS, Settleman J (2007) Epidermal growth factor receptor mutants from human lung cancers exhibit enhanced catalytic activity and increased sensitivity to gefitinib. Cancer Res 67: 2325-2330

Pao W, Miller VA, Politi KA, Riely GJ, Somwar R, Zakowski MF, Kris MG, Varmus H (2005) Acquired resistance of lung adenocarcinomas to gefitinib or erlotinib is associated with a second mutation in the EGFR kinase domain. PLoS Med 2: e73

Peruzzi B, Bottaro DP (2006) Targeting the c-Met signaling pathway in cancer. Clin Cancer Res 12: 3657-3660

Ruhe JE, Streit S, Hart S, Wong CH, Specht K, Knyazev P, Knyazeva T, Tay LS, Loo HL, Foo P, Wong W, Pok S, Lim SJ, Ong H, Luo M, Ho HK, Peng K, Lee TC, Bezler M, Mann C, Gaertner S, Hoefler H, Iacobelli S, Peter S, Tay A, Brenner S, Venkatesh B, Ullrich A (2007) Genetic alterations in the tyrosine kinase transcriptome of human cancer cell lines. Cancer Res 67: $11368-11376$

Salgia R (2006) c-Met inhibition. Clin Adv Hematol Oncol 4: 823-824

Sattler M, Pride YB, Ma P, Gramlich JL, Chu SC, Quinnan LA, Shirazian S, Liang C, Podar K, Christensen JG, Salgia R (2003) A novel small molecule met inhibitor induces apoptosis in cells transformed by the oncogenic TPR-MET tyrosine kinase. Cancer Res 63: $5462-5469$

Sawada K, Radjabi AR, Shinomiya N, Kistner E, Kenny H, Becker AR Turkyilmaz MA, Salgia R, Yamada SD, Vande Woude GF, Tretiakova MS, Lengyel E (2007) c-Met overexpression is a prognostic factor in ovarian cancer and an effective target for inhibition of peritoneal dissemination and invasion. Cancer Res 67: 1670-1679

Schmidt L, Duh FM, Chen F, Kishida T, Glenn G, Choyke P, Scherer SW, Zhuang Z, Lubensky I, Dean M, Allikmets R, Chidambaram A, Bergerheim UR, Feltis JT, Casadevall C, Zamarron A, Bernues M, Richard S, Lips CJ, Walther MM, Tsui LC, Geil L, Orcutt ML, Stackhouse T, Lipan J, Slife L, Brauch H, Decker J, Niehans G, Hughson MD, Moch H, Storkel S, Lerman MI, Linehan WM, Zbar B
(1997) Germline and somatic mutations in the tyrosine kinase domain of the MET proto-oncogene in papillary renal carcinomas. Nat Genet 16: $68-73$

Schmidt L, Junker K, Nakaigawa N, Kinjerski T, Weirich G, Miller M, Lubensky I, Neumann HP, Brauch H, Decker J, Vocke C, Brown JA, Jenkins R, Richard S, Bergerheim U, Gerrard B, Dean M, Linehan WM, Zbar B (1999) Novel mutations of the MET proto-oncogene in papillary renal carcinomas. Oncogene 18: $2343-2350$

Schmidt L, Junker K, Weirich G, Glenn G, Choyke P, Lubensky I, Zhuang Z, Jeffers M, Vande Woude G, Neumann H, Walther M, Linehan WM, Zbar B (1998) Two North American families with hereditary papillary renal carcinoma and identical novel mutations in the MET protooncogene. Cancer Res 58: $1719-1722$

Sharma SV, Bell DW, Settleman J, Haber DA (2007) Epidermal growth factor receptor mutations in lung cancer. Nat Rev Cancer 7: $169-181$

Shepherd FA, Rodrigues Pereira J, Ciuleanu T, Tan EH, Hirsh V, Thongprasert S, Campos D, Maoleekoonpiroj S, Smylie M, Martins R, van Kooten M, Dediu M, Findlay B, Tu D, Johnston D, Bezjak A, Clark G, Santabarbara P, Seymour L (2005) Erlotinib in previously treated non-small-cell lung cancer. $N$ Engl J Med 353: 123 - 132

Shigematsu H, Gazdar AF (2006) Somatic mutations of epidermal growth factor receptor signaling pathway in lung cancers. Int J Cancer 118: $257-262$

Smolen GA, Sordella R, Muir B, Mohapatra G, Barmettler A, Archibald H, Kim WJ, Okimoto RA, Bell DW, Sgroi DC, Christensen JG, Settleman J, Haber DA (2006) Amplification of MET may identify a subset of cancers with extreme sensitivity to the selective tyrosine kinase inhibitor PHA-665752. Proc Natl Acad Sci USA 103: 2316-2321

Song L, Turkson J, Karras JG, Jove R, Haura EB (2003) Activation of Stat3 by receptor tyrosine kinases and cytokines regulates survival in human non-small cell carcinoma cells. Oncogene 22: 4150-4165

Stegmaier K, Corsello SM, Ross KN, Wong JS, Deangelo DJ, Golub TR (2005) Gefitinib induces myeloid differentiation of acute myeloid leukemia. Blood 106: $2841-2848$

Tsarfaty I, Rong S, Resau JH, Rulong S, da Silva PP, Vande Woude GF (1994) The Met proto-oncogene mesenchymal to epithelial cell conversion. Science 263: $98-101$

Wong KK (2007) HKI-272 in non small cell lung cancer. Clin Cancer Res 13: s4593 - s4596 